\title{
TRES NUEVAS OBRAS DEL ESCULTOR CRISTÓBAL RAMOS
}

\author{
THREE NEW WORKS BY THE SCULPTOR \\ CRISTÓBAL RAMOS
}

\author{
José Manuel Moreno Arana \\ morenoarana@gmail.com
}

\begin{abstract}
Se presentan tres piezas inéditas del escultor sevillano Cristóbal Ramos (1725-1799) conservadas en Jerez de la Frontera (Cádiz). Destaca el retrato firmado del canónigo Francisco del Río (1748), que pasa a ser su más temprana obra conocida.

Palabras clave: escultura; Cristóbal Ramos; Sevilla; Jerez de la Frontera; siglo XVIII.
\end{abstract}

Three new works by the Sevillian sculptor Cristóbal Ramos (1725-1799), preserved in Jerez de la Frontera (Cádiz), are presented. The signed portrait of the canon Francisco del Río (1748) is highlighted because it becomes his earliest known work.

Keywords: sculpture; Cristóbal Ramos; Seville; Jerez de la Frontera; $18^{\text {th }}$ century.

Cristóbal Ramos (1725-1799) fue uno de los últimos escultores barrocos de la escuela sevillana. Alcanzó una posición preeminente en el contexto hispalense de la segunda mitad del siglo XVIII, remarcada por su labor docente dentro de la Real Escuela de Nobles Artes. Una vinculación al academicismo ilustrado que, sin embargo, no estuvo reñida con la práctica de una imaginería de hondas raíces tradicionales e incluso de cierto toque popular, como manifiesta la corriente elección de formatos reducidos y el uso de materiales como el barro y las telas encoladas en sus obras. Ello explica el gran éxito que alcanzarían sus trabajos tanto en la ciudad como en su amplia zona de influencia ${ }^{1}$.

${ }^{1}$ Sobre Cristóbal Ramos ver MONTESINOS MONTESINOS, Carmen: El escultor sevillano D. Cristóbal Ramos (1725-1799). Sevilla, 1986; GONZÁLEZ GÓMEZ, Juan Miguel y CARRASCO TERRIZA, Manuel Jesús: Catálogo Monumental de la Provincia de Huelva. Vol. I. Huelva, 1999, pp. 30, 39 y 97; RECIO MIR, Álvaro: "El escultor Cristóbal Ramos al servicio del Cabildo de la Catedral de Sevilla", Boletín de Bellas Artes, 
En esta ocasión, vamos a dar a conocer tres piezas inéditas que se suman a su ya extenso catálogo. Una de ellas está firmada y pertenece al poco cultivado género de retrato. Las otras dos, de carácter religioso, se le pueden atribuir por sus estrechas similitudes con otras documentadas o firmadas. Todas se conservan en diferentes edificios religiosos de Jerez de la Frontera.

La primera de estas obras se halla en la iglesia de San Mateo, desconociéndose las circunstancias de su llegada a este templo (Figura 1). Actualmente se sitúa en una pequeña hornacina abierta en el banco del retablo de la capilla de Villacreces. Es un retrato de medio cuerpo de un clérigo realizado en barro cocido policromado. Mide unos 27 centímetros de alto, incluyendo el pedestal sobre el que asienta la figura, de una altura de $10 \mathrm{y}$ que ha sido modelado formando un mismo bloque. La anchura total del conjunto es de 22 centímetros, teniendo 14,5 de profundidad. En el lado posterior de la peana se ha grabado la firma": "Xptobal Antonio Ramos/ Facieba año de 1748"3 (Figura 2). Por su parte, sobre la

29, 2001, pp. 153-159; ROS GONZÁLEZ, Francisco Sabas: "Dos imágenes de Cristóbal Ramos para la Hermandad del Rosario de San Pablo", Boletín de las Cofradías de Sevilla, 509, 2001, pp. 34-36; SÁNCHEZ DE LOS REYES, Francisco Javier: "La Virgen de las Aguas... ¿en Valladolid? Una imagen atribuida a Cristóbal Ramos en el Museo Nacional de Escultura", Boletín de las Cofradías de Sevilla, 533, 2003, pp. 498-499; HALCÓN, Fátima: "La Hermandad de Ntra. Sra. del Rosario del convento de Regina Angelorum de Sevilla", en IV Simposio sobre Hermandades de Sevilla y su provincia. Sevilla, 2003, pp. 198-199; RODA PEÑA, José: "Patrimonio artístico", en El Oratorio de San Felipe Neri de Sevilla. Historia y Patrimonio Artístico. Córdoba, 2004, pp. 465, 476, 485-487, 492, 495496, 611 y 615; RAMOS SUÁREZ, Manuel Antonio: "El escultor Cristóbal Ramos y la iconografía rosariana en Sevilla. La Virgen del Rosario de Marchena (Sevilla)", Boletín de las Cofradías de Sevilla, 559, 2005, pp. 616-619; SANTOS MÁRQUEZ, Antonio Joaquín: "Una nueva obra del escultor Cristóbal Ramos", Boletín de Bellas Artes, XXXIV, 2006, pp. 159-167; RECIO MIR, Álvaro: "La escultura sevillana, la Academia de San Fernando y el ocaso de la escuela", Academia, 104-105, 2007, pp. 141-142 y 150; LÓPEZ ALFONSO, Jesús: "La Inmaculada Concepción de la Capilla de las Doncellas de la Catedral de Sevilla”, Boletín de las Cofradías de Sevilla", 598, 2008, pp. 1052-1053; RODA PEÑA, José: "Prendas devocionales e imágenes singulares. La escultura en los conventos sevillanos de clausura", en La ciudad oculta. El universo de las clausuras de Sevilla, Sevilla, 2009, pp. 106107; RODA PEÑA, José: "La escultura barroca del siglo XVIII en Andalucía occidental", Cuadernos de Estepa, 4, 2014, pp. 93-94; y REYES DE LA CARRERA, Manuel Ramón: "Un niño Jesús de Cristóbal Ramos y un calvario genovés en Trigueros", Cuadernos de Estepa, 4, 2014, pp. 216-220.

${ }_{2}^{2}$ Damos las gracias a Javier Jiménez López de Eguileta y a Pablo Pomar Rodil por informarnos de la existencia de la firma de Cristóbal Ramos sobre esta obra y a la hermandad del Desconsuelo de Jerez por las facilidades dadas para su estudio.

${ }^{3}$ Curiosamente, firma con sus dos primeros nombres de pila, ya que fue bautizado como Cristóbal Antonio José. MONTESINOS MONTESINOS, C: El escultor sevillano..., op. cit., p. 14. 
espalda del retratado se puede leer con cierta dificultad una inscripción que identifica al personaje y que puede trascribirse como: "Soi D. Fran ${ }^{\mathrm{co}}$ del/ Rio (Soto) Can\% de la S ${ }^{\mathrm{a}}$ Ygles $^{\mathrm{a}}$ / de Sevilla”.

El nombre de Francisco Domingo del Río Soto y Torres aparece entre los expedientes de limpieza de sangre de la catedral de Sevilla, en concreto en uno fechado el 7 de noviembre de 1731 por el que solicita el cargo previo de coadjutor de canónigo. Por este documento sabemos que había nacido en Sevilla el 21 de septiembre de 1704, por lo que en 1748 tendría unos cuarenta y cuatro años, algo que parece cuadrar con la edad con la que fue retratado por Cristóbal Ramos. Los datos genealógicos apuntados no permiten establecer ningún tipo de relación con Jerez, por lo que sigue resultando todo un misterio la llegada de su retrato a la ciudad ${ }^{4}$.

Francisco del Río es representado con la indumentaria de canónigo con capa y muceta negras, sobrepelliz o roquete blanco y bonete también negro que porta en una de las manos. La capa envuelve el torso en amplios y elegantes pliegues y se recoge debajo de los brazos. La posición es frontal, aunque se percibe un giro muy leve a la derecha de la cabeza. Esta ha sido modelada con detalle y realismo. En el rostro, algo orondo, destacan unos ojos grandes y vivaces, si bien la expresión del semblante es comedida, esbozando únicamente los labios una tenue sonrisa. Más retórica resulta la pose de la mano derecha sobre el vientre o la delicadeza con la que la izquierda sostiene el bonete, teatralmente dejado caer sobre el pedestal. Esta peana remarca el aspecto barroco del conjunto a través de sus perfiles cóncavos y su ornamentación, entre la que sobresale, en el frontal, una plástica máscara formada por rizadas hojas de acanto, mientras que en cada lateral aparece una flor.

La escultura posee una especial significación entre la obra de Ramos por varias razones. En primer lugar, por ser la más temprana de las piezas seguras de su autor, realizada con la edad de veintitrés años. Ello demuestra que ya entonces trabajaba de manera independiente de su padre, Juan Isidoro Ramos, también escultor, siendo este retrato además testimonio del alto nivel de calidad que poseía ya por aquellas fechas. Por otro lado, es interesante la circunstancia de ser un trabajo profano, excepcional dentro de un contexto donde primaba aún la temática religiosa. En este sentido, de Ramos apenas hay noticias de unas pocas obras de carácter mitológico muy posteriores, ya en su época de profesor de la Escuela de las Tres Nobles Artes de la ciudad 5 . En cambio, llama la atención que contemos con otro retrato salido de sus manos, el del célebre ilustrado Gaspar Melchor de Jovellanos,

${ }^{4}$ Archivo de la Catedral de Sevilla, Secretaría, Pruebas de Sangre, leg. 7596, exp. 93. Ver también SALAZAR MIR, Adolfo: Los expedientes de limpieza de sangre de la Catedral de Sevilla (genealogías). T. II. Madrid, 1996, p. 39.

5 RECIO MIR, Á.: "La escultura sevillana...", op. cit., pp. 141 y 150. 
fechado en 1770 y perteneciente al Museo Nacional de Artes Decorativas ${ }^{6}$. La distancia temporal de veintidós años entre ambas esculturas no impide ver en ellas una concepción muy semejante: terracotas policromadas de pequeño formato, con acabado minucioso y realista de las cabezas, similar tratamiento de los paños o cierta afectación en la gesticulación de las manos. En ambas igualmente la firma y la inscripción donde se identifica al representado se disponen en el dorso de la figura. La gran diferencia está, sin embargo, en el hecho de que el retrato de Jovellanos es de cuerpo entero y sedente y no de busto como el de Francisco del Río. En cualquier caso, la aparición de dos retratos firmados por el artista en fechas distantes hace sospechar que no debieron de ser casos únicos dentro de su producción y que quizás pudo especializarse en este singular tipo de escultura.

Esta obra es además el primer testimonio documentado de sus contactos con miembros del cabildo de la catedral hispalense, para el que este escultor llevó a cabo diferentes trabajos décadas más tarde. Así, en 1784 modeló por encargo de esta institución la escultura de San Bernardo de la portada principal de la parroquia sevillana de este santo. Años más tarde, en 1787, se le encomienda la realización de una monumental figura de barro con la alegoría de la Fe para rematar la cúpula de la iglesia del Sagrario, aunque esta pieza ni siquiera llegó a instalarse en el lugar para el fue concebida ya que sabemos que sufrió daños durante su cocción ${ }^{7}$. Pese a este lamentable hecho, consta que hizo en 1793 para el canónigo Pedro José del Campo unas imágenes de San José, Santa Ana y San Joaquín con destino a la capilla de la Estrella de la catedral ${ }^{8}$. Junto a ello, dentro del catálogo del artista existen varias atribuciones de esculturas veneradas en el primer templo sevillano?.

Las otras dos obras que presentamos aquí responden a dos temáticas religiosas que fueron tratadas por Ramos con frecuencia, creando unos modelos que debieron de tener gran éxito pues los repitió en diversas ocasiones y con escasas variaciones. Nos referimos al Nacimiento y a la Dolorosa.

En el conocido como Museo Carmelitano de la Provincia Bética, anexo a la basílica de Nuestra Señora del Carmen de Jerez, se conserva un Nacimiento de pequeño tamaño y con la habitual combinación de barro y telas encoladas (Figura 3). Se compone de las figuras del Niño Jesús en su pesebre, la Virgen y San José adorándolo, la mula, el buey y una especie de rompimiento de gloria, en relieve, con tres cabezas de querubines rodeadas de ráfagas, el elemento quizás de mayor

${ }^{6}$ Ver ficha del catálogo de la Red Digital de Colecciones de Museos de España: http:// ceres. mcu.es/pages $/$ Main? idt $=30970 \&$ inventary $=$ CE $/ 1950 / 14 \&$ table $=$ FMUS\&museum $=$ MNAD (Consultado el 26-9-2016).

7 Sobre ambos trabajos ver RECIO MIR, Á.: "El escultor Cristóbal Ramos...”, op. cit., pp. 155-159.

${ }^{8}$ MONTESINOS MONTESINOS, C.: El escultor sevillano..., op. cit., p. 48.

9 Ibidem, pp. 67 y 71; y LÓPEZ ALFONSO, J.: "La Inmaculada Concepción...”, op. cit. 
originalidad del conjunto. De los dos grupos escultóricos del mismo tema sobre los que la autoría de Cristóbal Ramos está confirmada, el de la colección de José Cortines Pacheco en Lebrija y el más tardío de la Escuela de Cristo de Sevilla $(1798)^{10}$, es con el primero con el comparte afinidades más estrechas. Igualmente, es innegable la relación con otros belenes atribuidos al artista, como el del monasterio de Santa Paula o, sobre todo, el de la iglesia de San Alberto, ambos en Sevilla ${ }^{11}$. Tanto en estos últimos como en el lebrijano se observan composiciones y modelos físicos muy parecidos en las figuras de María y José, reiterando posturas y ademanes, como el curvilíneo dibujo que describe el manto de la Virgen o la posición inestable del santo en dinámica actitud de arrodillarse o el modo en que sostiene con su mano derecha la capa. La riqueza del estofado de ambas imágenes, con un abigarrado dibujo de roleos vegetales y un uso intensivo del picado de lustre invita a encuadrar esta obra en torno a los años centrales del siglo XVIII, por tanto, en una etapa temprana dentro de la producción de su autor.

Finalmente, en la capilla del colegio de Nuestra Señora del Rosario, antiguo beaterio del Santísimo Sacramento, recibe culto una Dolorosa con las características tipológicas y morfológicas usuales en Ramos: arrodillada y con la mirada hacia arriba y las manos unidas en actitud implorante y de oración (Figura 4). Es el mismo modo en que fueron creadas sus dolorosas sevillanas documentadas, la Virgen de las Aguas (1772) y la Dolorosa de la Escuela de Cristo (h. 1798), además de otras atribuidas ${ }^{12}$. De nuevo, es una figura de tamaño menor al natural y ejecutada en terracota y telas encoladas. El estofado emplea la técnica del cincelado, propia de la policromía rococó, tanto en la túnica como en la delicada cenefa que a manera de encaje circunda el manto, por lo que pensamos que habría que situarla en las décadas centrales de la segunda mitad del setecientos.

Fecha de recepción: 30 de septiembre de 2016

Fecha de aceptación: 4 de enero de 2017

\footnotetext{
${ }^{10}$ MONTESINOS MONTESINOS, C.: El escultor sevillano..., op. cit., pp. 36-37.

${ }^{11}$ Ibidem, p. 36.

12 Ibid., pp. $41-43$ y 52-53.
} 


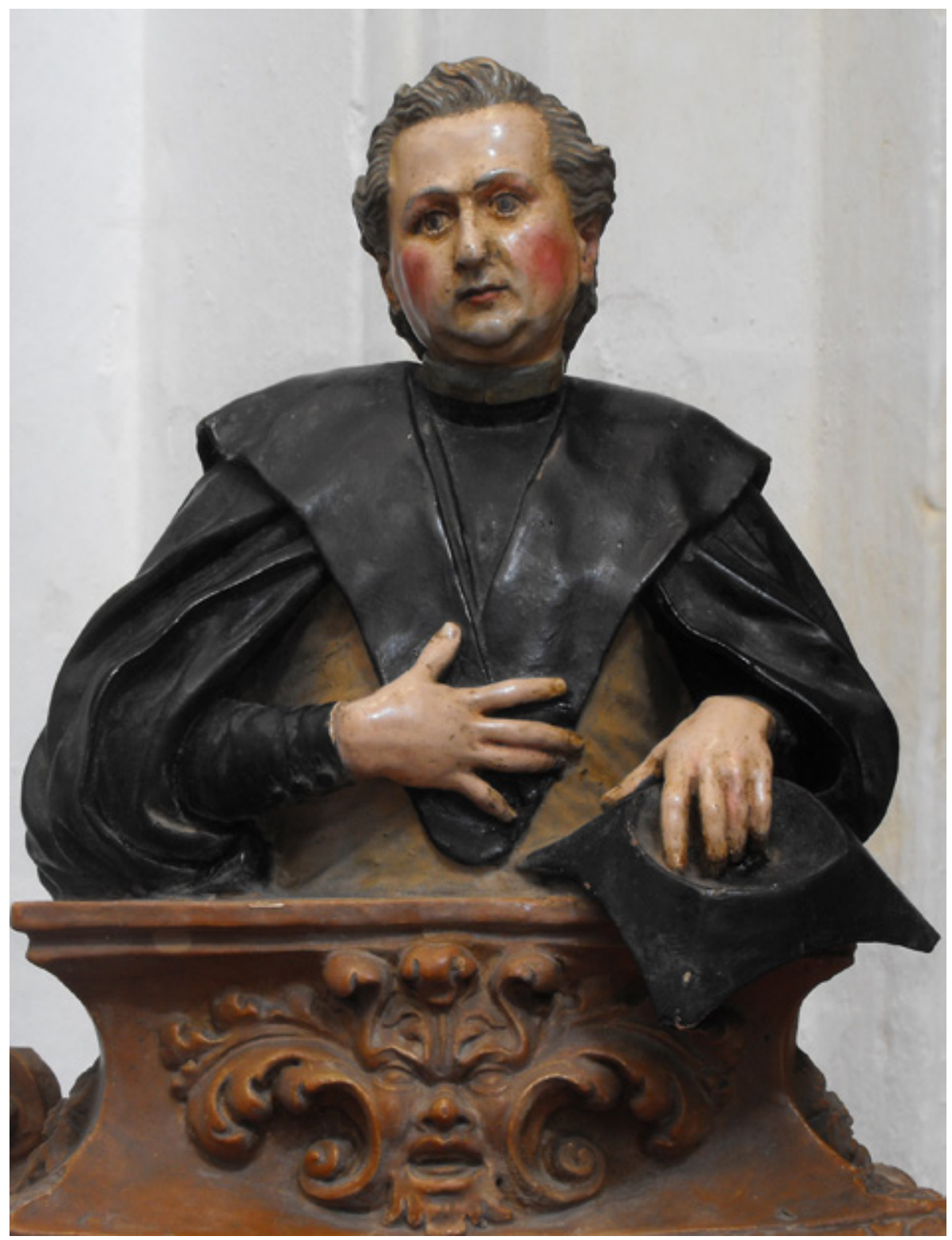

Figura 1. Cristóbal Ramos, Retrato de Francisco del Río, 1748, iglesia de San Mateo, Jerez de la Frontera. 


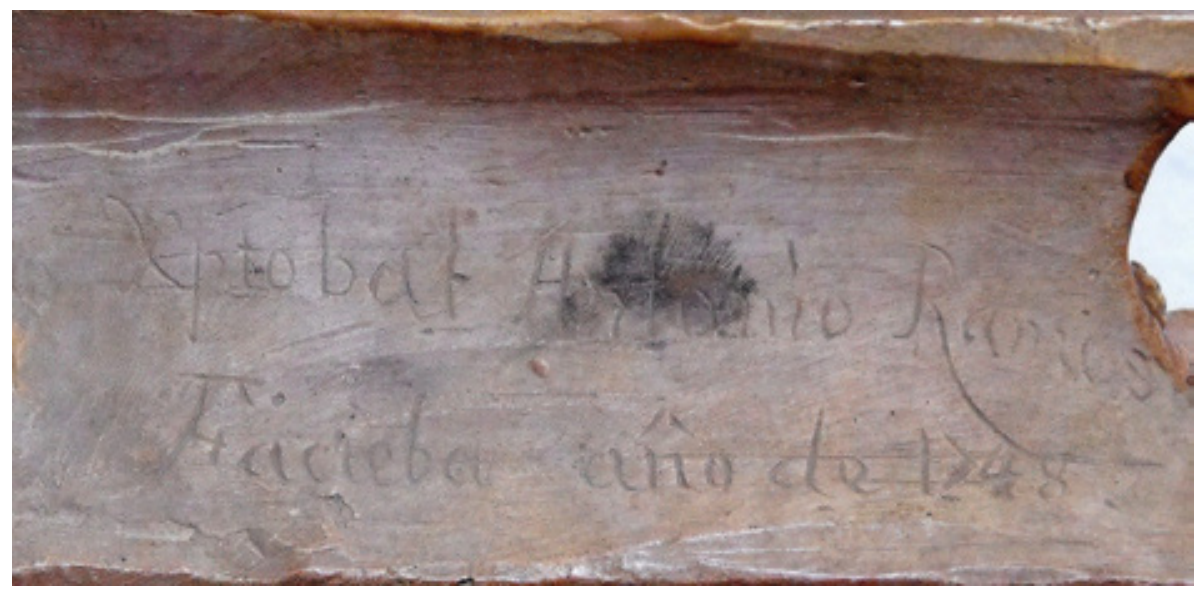

Figura 2. Cristóbal Ramos, Retrato de Francisco del Río (detalle de la firma), 1748, iglesia de San Mateo, Jerez de la Frontera.

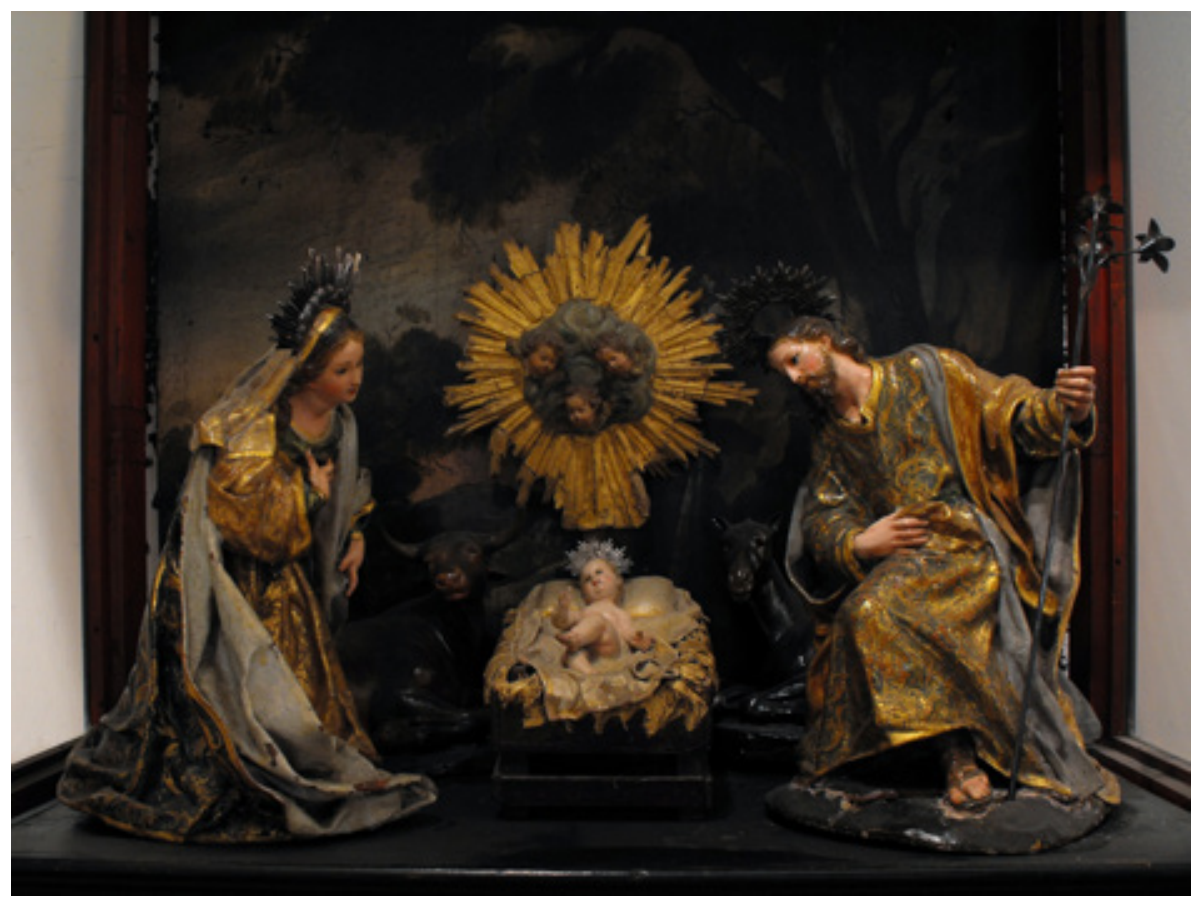

Figura 3. Cristóbal Ramos (atribución), Nacimiento, Museo Carmelitano de la Provincia Bética, Jerez de la Frontera.

LABORATORIO DE ARTE 29 (2017), pp. 819-826, ISSN 1130-5762 e-ISSN 2253-8305 - DOI http://dx.doi.org/10.12795/LA.2017.i29.46 


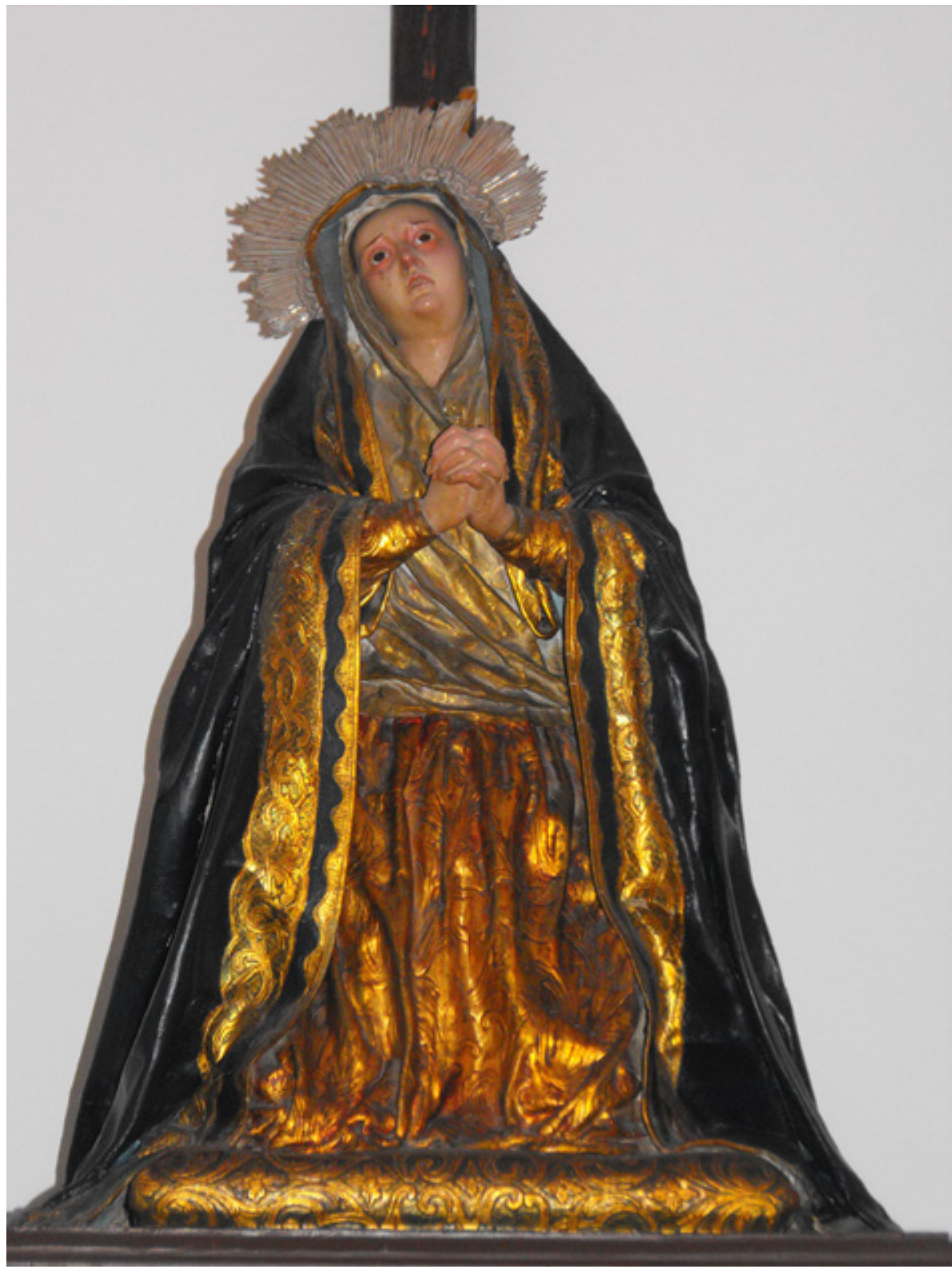

Figura 4. Cristóbal Ramos (atribución), Dolorosa, capilla del colegio de Nuestra Señora del Rosario, Jerez de la Frontera. 